\title{
O SABER INCONSCIENTE DO SUJEITO E O DESEJO DO ANALISTA NA CLÍNICA DAS TOXICOMANIAS
}

\section{ARTIGO ORIGINAL}

ROCHA, Lorena Fabiani da ${ }^{1}$

ROCHA, Lorena Fabiani da. O saber inconsciente do sujeito e o desejo do analista na clínica das toxicomanias. Revista Científica Multidisciplinar Núcleo do Conhecimento. Ano 05, Ed. 04, Vol. 01, pp. 152-161. Abril de 2020. ISSN: 2448-0959, Link de acesso: https://www.nucleodoconhecimento.com.br/psicologia/saberinconsciente

\section{RESUMO}

O atendimento clínico a pacientes toxicômanos exige que se observem dimensões inconscientes do sujeito que se droga e do analista que o acompanha, considerando que tais dimensões antecedem e implicam a condição de dependência do paciente. Desta forma, este trabalho tem por objetivo esclarecer perspectivas psicanalíticas que norteiam a abordagem do fenômeno toxicômano no setting de atendimento. Tomaram-se conceitos como "inconsciente" e "desejo do analista" a fim de elucidar a forma como a situação analítica constitui um tratamento individualizante e se contrapõe ao método da psiquiatria clássica. Para tanto, ressalta-se a existência de um saber particular em cada paciente acerca de sua drogadição, o qual não foi previsto pela nosologia médica. Considera-se, pois, insuficiente a técnica psiquiátrica e se explora uma abordagem que busca melhor interpretar a toxicomania, tendo como ferramenta basilar o desejo do analista. Além dos conceitos centrais trazidos pelo título, o trabalho também passa pelas noções de "linguagem", "mal-estar na cultura", "eu", "monomania", "castração" e "maturação pulsional". A pesquisa partiu do método de investigação bibliográfica, tangendo o tema "Toxicodependência" no âmbito da

\footnotetext{
${ }^{1}$ Graduanda em Psicologia.
} 
Psicanálise e da Psiquiatria clássica. Recorreu-se à literatura de autores consagrados que entrecruzam tais saberes, como Freud, Lacan e Bercherie.

Palavras-chave: Toxicomania, análise, atendimento clínico, psiquiatria clássica.

\section{INTRODUÇÃO}

A toxicomania é um fenômeno que necessita ser estudado para além da prática drogadictiva. Em vista disso, a psicanálise pressupõe uma ética e opera a partir de um saber inconsciente que produz gozo. A descoberta desse saber decorre da experiência de um processo de análise. Assim, ao admitir o desejo que guarda a verdade última e particular do sujeito, o método postulado por Sigmund Freud se contrapõe à maneira como a psiquiatria clássica oriunda de Pinel lidou com esse fenômeno até o início do séc. XX.

A presente pesquisa é norteada pela teoria psicanalítica, ou seja, considera a descoberta do saber inconsciente que afeta o ser falante de um modo individual, que faz da história de vida de cada sujeito uma forma específica de habitar a linguagem, em consonância com sua economia libidinal. Esta linguagem, por sua vez, nos faz habitar o mal-estar da cultura e nos confronta com objetos ofertados pelo discurso do capitalista para tamponar a falta irreparável que marca o existir humano. Nesse sentido, o desejo do analista interpela o discurso da ciência que foraclui o sujeito da fala, da linguagem, da subjetividade. Partindo dessa premissa, a investigação objetiva responder a seguinte questão: o que é velado pela toxicomania, e como opera o desejo do analista na clínica das toxicomanias?

Portanto, o objetivo deste trabalho é assinalar como o desejo do analista se constitui uma ferramenta clínica e de que maneira aborda a intoxicação, a partir do inconsciente e da pulsão. A importância desta pesquisa está em tomar o fenômeno no seu duplo valor social e subjetivo, ampliando a visão reducionista e a abordagem fenomênica do tema. Para cumprir o objetivo, o método utilizado em nosso estudo foi a pesquisa bibliográfica de autores consagrados como Freud, Lacan e Bercherie, que abordam a toxicodependência no âmbito da Psicanálise e da Psiquiatria Clássica. A pesquisa foi 
resultado do Projeto de Iniciação Científica da Universidade Veiga de Almeida (PIC UVA 2019) e orientada pela professora e psicanalista Clara Lúcia Inem.

\section{RESULTADOS}

Do presente estudo, derivou-se a constatação de que todo saber advém da manipulação de uma linguagem que é anterior a ele mesmo (LACAN, 1954). Trata-se da linguagem humana, essencialmente simbólica e particular, de modo que aqui, tem posse exclusiva do sentido no fenômeno toxicomaníaco. Dessa forma, essa investigação bibliográfica reafirma um método que se opõe ao modelo nosológico da psiquiatria, ao subjetivar o fenômeno em questão.

Percebeu-se que, a linguagem tem primazia no funcionamento do sujeito e denuncia a intoxicação como processo secundário. A partir daí entende-se que, a prática da droga vela o verdadeiro sintoma com as interpretações pessoais do paciente desde 0 início de sua constituição. Infere-se, então, que o imperativo do tratamento é a atribuição de um simbolismo às manifestação do sujeito (LACAN, 1955), e alcançamos que, o simbolismo presente na repetição toxicômana diz de uma desilusão do paciente na relação ao outro (FREUD, 1927). Posto isto, primeiro clarifica-se a condição de assujeitamento do paciente, para então, considerar a prática drogadictiva como enigma.

Por fim, observou-se o substancial papel do desejo do analista no manejo desse fenômeno. Isto porque, este desejo funda saídas, porquanto se oferece como lugar (QUINET, 2000) de instalação do desejo amadurecido do paciente. É nessa direção que o desejo do analista aponta: em lugar da repetição monótona e do curto- circuito pulsional promovido pela intoxicação, conduzir o sujeito à um desejo maturado, que reconhece e investe em si mesmo. Essas são as questões que se nos apresentam: uma intoxicação da linguagem onde fracassa o significante e não possibilita que o corpo seja metaforizado pelo saber inconsciente. 


\section{DISCUSSÃO}

\section{DA TOXICOMANIA COMO PRODUTO DE UM MAL-ESTAR SUBJETIVADO NO LUGAR DE SIGNO EPISTEMOLÓGICO}

A partir de uma discussão sobre a possível origem da religiosidade em "O Mal-estar na Civilização", Freud (1930) especifica alguns mecanismos inconscientes que o ser humano engendra para lidar com a angústia de habitar um mundo com o qual descobre não ter relação de unidade, e que constitui um estorvo na sua busca pela felicidade. Dentre esses mecanismos participa a intoxicação, como tentativa de reaver uma satisfação vivida no início da vida, e que não podendo ser recuperada, leva à repetição.

Assim, reconhecemos que o eu atual do sujeito é o que se desdobrou de sua versão infantil (FREUD, 1930) após uma desilusão. No entanto, o eu recobre uma camada inconsciente, que ao invés de afigurar o sujeito como uno, diz de seus impulsos mais passivelmente postos à prova de dissecação, conforme guardam desejo. Toma-se, então, o fenômeno toxicomaníaco no que ele se relaciona a esses impulsos. Por isso, é ineficaz observar e classificar a prática drogadictiva objetivamente como propõe a psiquiatria clássica. Este método levaria o analista a condescender com o analisante quando este traz a droga como uma marca identitária. Sendo assim, à medida em que o analista não responde do lugar esperado pelo paciente - qual seja, o lugar de ensino - tornando seu ato tão desconhecido quanto o que se esconde sob o eu do sujeito, comparece uma doutrina analítica que abriga uma lacuna indispensável, que se contrapõe ao saber da psiquiatria, o qual já existe esgotado antes da experiência com o paciente.

Para fundar um caminho alternativo, entende-se que o paciente precisa primeiro fiarse na crença de que o profissional conhece acerca do que ele traz como desordem. No entanto, é apenas quando o analista se vale de tal suposição para ocasionar que o sujeito reconheça a causa em si próprio, que se acha o sucesso indubitável de um procedimento. 
Entende-se aqui que, a intoxicação não é o sintoma, mas vela mecanismos simbólicos que já tem valor de palavra e carregam seu próprio sentido (LACAN, 1953). Posto isto, tomar outros caminhos para decifração do enigma faria apenas embaraçar as coisas. Dar nome ao que já traz em si um significante, nos coloca um caminho novo fora do sujeito, e por isso, sem saída.

Ainda assim - nos rememora Bercherie (1989), Pinel não prescindiu de formular uma vasta nosografia que o fez qualificar a toxicomania como loucura de impulso, mania sem delírio, e por último, monomania. No entanto, a psicanálise não consente com a atitude de findar o entendimento das toxicomanias como impulsos de causa moral, tomando-as unicamente por excessivas paixões proibidas e duradouras. Embora considere-se no ato toxicômano uma tentativa de subverter a cultura de moderação dos impulsos, não se procede para dominá-los, ao contrário, serve-se deles para que o sujeito ascenda a mecanismos mais maduros. Assim, a análise investiga os afetos depositados na droga, e a própria constância na drogadição é tomada como efeito da causa, nunca como a causa em si mesma.

A psiquiatria por sua vez, percebeu as causas morais como as mais numerosas e produtoras de um tipo de 'perturbação visceral' (BERCHERIE, 1989), propagando a loucura de impulso por irradiação no organismo. É interessante notar que para a psicanálise, a causa do fenômeno toxicômano também faz um trajeto por irradiação, mas esta é a irradiação em cadeia significante que o núcleo discursivo do sujeito percorreu até ser observado clinicamente como fenômeno.

Diante disto, encontra-se nas considerações de Freud (1930), que para elucidar a qualidade daquilo em função de que age o desejo do analista, acata-se a prática drogadictiva naquilo em que objetiva proteção contra a frustração com o mundo real. A eficácia dos tóxicos está em insensibilizar o paciente frente às infelicidades da vida neurótica, de maneira que a droga subverte a química do corpo e faz o sujeito gozar mesmo permanecendo imerso no mundo hostil da castração. Desta forma, o psicanalista deve atentar-se para o simbolismo latente na eficácia da droga, considerando que na luta pela felicidade, a intoxicação produz prazer imediato e 
sensação de independência do mundo externo, o qual está posto para promover desprazer.

Em vista disso, considera-se que o propósito da vida humana (FREUD, 1930) é justamente a busca pela felicidade e a perseguição do prazer. $O$ sujeito pretende 0 sucesso da economia libidinal e funciona para a evitação do sofrimento visando a plena satisfação. Neste sentido, o princípio do prazer dita rotas que objetivam a homeostase psíquica, mesmo nas suas aparições mais exageradas como a intoxicação. Deste modo, tal fenômeno constitui uma tentativa de neutralizar a neurose do sujeito, que está nesse mundo sem poder livrar-se dele.

Os entorpecentes atuam ao lado de impulsos que não se submeteram à civilização e tomaram objetos proibidos para se satisfazer. Considerando esta associação, a situação analítica percebe uma interdição sobre os impulsos que puderam ser reprimidos e admite que este interdito está para além da lei jurídica, em um nível subjetivo e inconsciente. O que se esquadrinha é a história edípica e particular de cada sujeito, naquilo em que velam a interdição simbólica e por vezes, leva o sujeito a rebelar-se contra a castração dos impulsos. (FREUD, 1930).

Concorda-se neste trabalho que, como principal fonte de sofrimento para o sujeito, as relações humanas repercutem na maneira como ele lida com suas pulsões. A despeito de o neurótico ter escolhido viver pela via do amor (FREUD, 1927), as vicissitudes das relações humanas podem levar o sujeito a escolhas objetais que o dispensem do perigo do amor. A predileção pela droga figura como uma dessas opções. Assim, encarrega-se aqui, do fenômeno toxicomaníaco como subtipo de um mal-estar que apesar de alcançar comumente os sujeitos neuróticos, é subjetivado por cada qual à sua maneira .

Posto isto, a psicanálise considera que o costume nominalista de observar a prática drogadictiva na realidade, continua se mostrando insuficiente para dar conta das consequências do real da interdição. É nesse sentido que, a técnica analítica transpõe seu foco para um terreno não observável à primeira vista e que não garante nomeações antecipadas, à medida em que não está preocupada em se estabelecer 
como um saber absoluto. Deste modo, não se objetiva com o presente trabalho, traçar um inventário completo de como os conceitos psicanalíticos oferecem solução para a questão toxicomaníaca, mas ao contrário, resgatar a noção central de sujeito do inconsciente (FREUD, 1900) e de que forma o analista o convoca através do fenômeno toxicomaníaco.

\section{O SABER INCONSCIENTE DO SUJEITO}

Para fundar o instrumento com o qual aborda-se o sujeito deste trabalho, "A Interpretação dos Sonhos" (FREUD, 1900, p. 406) traz noções que faltaram à psiquiatria de Pinel. Aqui, funda-se um terceiro elemento sem o qual não nos propomos a considerar a toxicomania. Tomamos então, a palavra no que ela instaura em si uma linguagem inconsciente e própria. Este elemento pode ser representado por atos de repetição com valor simbólico de discurso. Em vista disso, a reincidência na droga se dá pela crença do sujeito na fidedignidade com que o objeto o faz reviver uma satisfação passada, e aponta para uma linguagem inconsciente que fundamenta esta satisfação.

Para interpelar o prazer nesta repetição, considera-se a relação com o objeto como uma relação irrevogável de falta de objeto (LACAN, 1956). Esta relação entre paciente e objeto não é direta, mas transpassada por um furo. Em razão disso, ela não pode ser tomada como centro da situação analítica, mas serve-se dela para que a falta seja revelada ao sujeito.

Posto isto, o analista interpõe suas interpretações não em qualquer ponto, mas onde o derivado do significante da falta - a droga - simula tamponar o furo. Assim, não se alveja diretamente a intoxicação, mas o processo simbólico que ela encobre. Abordase então o conceito de castração (LACAN, 1956) como desdobramento da insuficiência mostrada pelo significante do Outro na constituição do sujeito. Por isso, entende-se que a potência do tratamento está em oportunizar a consciência de que, se mesmo o Outro em relação a quem o paciente submeteu seu eu, o levou ao desencanto, o substituto que tenta cumprir sua função também não lograra êxito. 
Assim, ao tomar o inconsciente como causa, o analista conduz o paciente fixado na droga a concluir que, mesmo os tóxicos quando fazem o corpo gozar aparentando silenciar a castração, não são capazes de aniquilar os efeitos dela.

Além disso, apesar de considerar-se as relações objetais como fundamentalmente perfuradas, sem que se possa centrar nelas, é a partir do furo que estrutura a busca na relação com a droga, que se encontra o desejo como verdade onde efetivamente o analista se atém. Ademais, há de se entender que primeiro o desejo afeta o sujeito e o sujeito já afetado por uma causa, afeta e escolhe o objeto (LACAN, 1958). Nessa relação, tal como o objeto, o próprio desejo também não tem um representante real, no entanto, à medida em que se localiza no próprio sujeito e não fora, ele tem chances de saídas mais autênticas para dar conta da castração. Parte-se então, da relação de hiância com o objeto droga à promoção do desejo, sem desconsiderar que mesmo aquilo que há de mais autêntico no sujeito não se alcança sem entraves.

Para tanto, assim como propôs Lacan (1959), este estudo toma a fantasia fundamental do sujeito como a forma fiel da relação de objeto. $O$ valor dessa fantasia na abordagem do fenômeno aqui discutido está em demonstrar não só o sujeito castrado e a droga da qual se vale como objeto de obstrução, mas sobretudo o desejo que movimenta seu aparelho psíquico. Ao conseguir se situar na própria fantasia através do seu desejo, o sujeito pode emergir como verdade, ao invés de eco do desejo de Outro alguém que outrora o cativara pela linguagem. Deste modo, o paciente reconhecerá um desejo fora de si, e que o seu próprio não admite objeto de satisfação, entrando assim, em outra etapa de sua constituição enquanto ser: a maturação pulsional.

Ademais, a intoxicação como investimento falho para dar nome à situação do sujeito no mundo simbólico, abre espaço para o surgimento do desejo, diante do qual este sujeito novamente intentará uma nomeação que também falhará (QUINET, 2000). A análise oportunizará que o sujeito sustente o discurso analítico que versa sobre essa inviabilidade. Ou seja, a subversão do verdadeiro sintoma se encontra em todos os casos, no próprio sujeito, conforme sustenta com o real de si a oposição ao que the constituiu simbólica e a imaginariamente. 
Posto isto, o analista preconiza não erradicar a prática drogadictiva, para dela localizar onde primeiro a satisfação do sujeito com o objeto se aloja. A escolha da droga parece garantir ao paciente ter encontrado uma forma de gozar que independe daquele por quem um dia veio a frustração - o Outro. No entanto, o que propõe Santiago (2001), é que no ato toxicomaníaco o sujeito parece não buscar um objeto substituto para sua relação ao Outro. Dessa maneira, o autor defende que o dito 'toxicômano' insinua tomar o gozo fálico como solução em si, quando mostra ter achado um objeto não genital que satisfaz sua busca e desqualifica a castração.

Em síntese, tomando por trilho a palavra do sujeito, descobre-se que o princípio regente da prática drogadictiva não mostra apenas a maximização do prazer e afastamento do desprazer como objetivo prático encerrado em si. Há no ínterim da dinâmica pulsional com o objeto, um gozo que se justifica na história - e apenas ali do sujeito. Portanto, o "[...] sujeito à medida que fala pode encontrar inteiramente sua resposta, seu retorno, seu segredo, seu mistério, no símbolo construído". (LACAN, 1954, p. 252).

\section{O DESEJO DO ANALISTA}

Introduz-se aqui, o último operador da análise sobre o qual iremos tratar: o desejo do analista. Depois de a pesquisa ter indicado quão primordial é centrar-se no saber inconsciente do sujeito e no seu desejo de mesma qualidade, mostrará as peculiaridades e implicações deste outro desejo. Nesse sentido, a despeito de o desejo do analista se presentificar em toda a análise, considera-se que é depois de oportunizar a aparição do saber inconsciente, que ele abre vias para que o sujeito se lance ainda em outra etapa. Dessa forma, depois que o paciente tomou o tratamento por aquilo que encaminha sua satisfação na droga ao seu amadurecimento pulsional, o analista com seu desejo atento (LACAN, 1960), provoca ainda o reconhecimento pelo sujeito sobre as características de seu próprio desejo.

Posto isto, passado o momento em que 0 analisante logrou sustentar o diálogo analítico e a impossibilidade de nomeação da sua condição desejante, ele será conduzido a perceber este desejo como aquilo que está vinculado à lei, como desejo 
do Outro. O desejo do analista trabalha para impulsionar o sujeito à transgressão da lei do Outro naquilo em que isto não significa descumprimento da lei constitucional da sociedade. Na verdade, promove-se em análise, o desassujeitamento à um estatuto simbólico que acabou por desregular o funcionamento autêntico desse sujeito. Assim, ao deparar-se com as verdadeiras causas da prática toxicomaníaca, o paciente se defronta com a inconsistência do Outro da lei (QUINET, 2000), no entanto, não é largado à sorte, uma vez que o desejo do analista passa a ocupar o lugar do desamparo, mas sem o Outro, sem a Lei.

Deste modo, ainda que este desejo passe a ocupar o lugar da inconsistência, ele mesmo guarda enigma (QUINET, 2000). Caso o sujeito procure o que pensa o analista sobre sua drogadição ou o que seu saber propõe para tal fenômeno, encontrará ausência de juízo, tornando impossível a interpretação desse desejo. Isto porque, a análise opera para que cada um julgue por si, fazendo apenas evidenciar o caráter dessas escolhas para que o sujeito não decida na ignorância dele próprio. Assim, é o saber do sujeito que funda o desejo do analista, e não o contrário, como sugere a Psiquiatria Clássica.

Além disso, a técnica analítica sequer objetiva "tratar a toxicomania", à medida em que o desejo do analista está em outro lugar, que não o de cura, libertação, expurgo ou socorro ao próximo. Ele se contrapõe, por exemplo, ao tratamento moral proposto por Pinel para dar conta de reorientar o desajuizado à razão (BERCHERIE, 1989). Enquanto a psiquiatria se instrumentalizou das instituições repressoras e da ideia de que a mente do doente era afetada por suas percepções, o analista também considera o ambiente e a realidade psíquica do sujeito, mas aposta num espaço de fala e na (re)constituição simbólica do inconsciente.

Por fim, o desejo do analista admite o desejo inconsciente do sujeito, mas difere deste no que não responde à demanda Alguma, e oferece lugar para que o desejo do sujeito também não prime por responder. O desejo do analista não diz de uma vontade pessoal de saber, mas é o lugar de um saber-a-menos (LACAN, 1969), uma posição que existe unicamente pela causa. Assim, esse desejo diz do objetivo supremo de 
possibilitar a existência do ser, apartando-o das amarras inconscientes contraídas por herança simbólica.

\section{CONCLUSÕES}

Empreendeu-se neste trabalho, uma considerável investigação teórica que conclui-se porém numa ideia concisa: a de que o fenômeno guarda uma história e esta é a história pessoal do sujeito que se droga. Assim, o desejo do analista é motor, não de cura, mas de questionamento sobre uma repetição com precedentes no próprio repetidor. É como em toda experiência de análise, uma clínica de descobrimento, mas não de saber à priori ou desejo de sarar, na qual o paciente constrói os próprios caminhos (LACAN, 1960) para o desenlace da repetição. Em vista disso, extrai-se a relevância deste trabalho no que ele reitera uma técnica que preza a autonomia do sujeito na prática drogadictiva.

A pesquisa nos leva a depreender que, como qualquer dos pacientes, o que busca 0 sujeito que se droga é a felicidade. Tomando isto em conta, o que a situação analítica questiona é "Atravessado por que parâmetros o sujeito a busca? O que ele sabe sobre a natureza dessa felicidade pretendida, por que faz o que faz para alcançá-la?".

Assim, tomamos a relevância do fenômeno toxicomaníaco no que seu estudo contribui socialmente e para a clínica do um a um, sem dar-se às generalizações, mesmo frente à recorrência do fenômeno. $O$ desejo do analista trabalha em vista de pôr luz sobre um saber inconsciente e particular. Neste sentido, à medida em que o eu é instância de desconhecimento no sujeito por estar referido ao Outro, mira-se uma esfera mais íntima para alcançar sua verdade. Para isto, empreende-se o seguinte caminho: a fala como acesso à verdade inconsciente do sujeito frente à intoxicação. Assim, admite-se não saber à priori sobre o que versa a fala do sujeito (LACAN, 1956), mas ela é tomada como via para o acesso ao mais além do fenômeno toxicomaníaco. 


\section{REFERÊNCIAS}

BERCHERIE, Paul. Os fundamentos da clínica: história e estrutura do saber psiquiátrico. Rio de Janeiro: Jorge Zahar, 1989.

FREUD, Sigmund. A interpretação dos sonhos, parte I. Edição Standard Brasileira das Obras Completas de Sigmund Freud, vol. IV. Rio de Janeiro: Imago,1996.

A interpretação dos sonhos, parte II. Edição Standard Brasileira das Obras Completas de Sigmund Freud, vol. V. Rio de Janeiro: Imago,1996.

. O Mal Estar na Civilização. Edição Standard Brasileira das Obras Completas de Sigmund Freud, vol. XXI. 2. ed. Rio de Janeiro: Imago, 1988. LACAN, Jacques. O seminário, livro 1: os escritos técnicos de Freud. 2. ed. Rio de Janeiro: Jorge Zahar, 2009.

. O seminário, livro 2: o eu na teoria de Freud e na técnica da psicanálise. 2. ed. Rio de Janeiro: Jorge Zahar, 2010.

. O seminário, livro 4: a relação de objeto. Rio de Janeiro: Jorge Zahar, 1995.

. O seminário, livro 6: o desejo e sua interpretação. 1. ed. Rio de Janeiro: Jorge Zahar, 2016.

O seminário, livro 7: a ética da psicanálise. Rio de Janeiro: Jorge Zahar, 2008.

O seminário, livro 11: os quatro conceitos fundamentais da psicanálise. 2. ed. Rio de Janeiro: Jorge Zahar, 2008.

O seminário, livro 17: o avesso da psicanálise. Rio de Janeiro: Jorge Zahar, 1992. 
QUINET, Antonio. A descoberta do inconsciente: do desejo ao sintoma. 7. ed. Rio de Janeiro: Jorge Zahar, 2018.

SANTIAGO, Jésus. A droga do toxicômano: uma parceria cínica na era da ciência. 2. ed. Belo Horizonte: Relicário Edições, 2017.

Enviado: Março, 2020.

Aprovado: Abril, 2020. 